Cite this: Dalton Trans., 2014, 43, 11516

Received 20th March 2014, Accepted 27th April 2014

DOI: $10.1039 / c 4 d t 00843 j$

www.rsc.org/dalton

\section{Formation of a Eu(III) borate solid species from a weak Eu(III) borate complex in aqueous solution $\uparrow$}

\author{
Juliane Schott, ${ }^{a, b}$ Jerome Kretzschmar, ${ }^{a}$ Margret Acker, ${ }^{\text {tb }}$ Sascha Eidner, ${ }^{c}$ \\ Michael U. Kumke, ${ }^{c}$ Björn Drobot, ${ }^{a}$ Astrid Barkleit, ${ }^{\text {ad }}$ Steffen Taut, ${ }^{b}$ Vinzenz Brendler ${ }^{a}$ \\ and Thorsten Stumpf $f^{\text {a,d }}$
}

\begin{abstract}
In the presence of polyborates (detected by ${ }^{11} \mathrm{~B}-\mathrm{NMR}$ ) the formation of a weak Eu(III) borate complex (lg $\beta_{11} \sim 2$, estimated) was observed by time-resolved laser-induced fluorescence spectroscopy (TRLFS). This complex is a precursor for the formation of a solid Eu(II) borate species. The formation of this solid in solution was investigated by TRLFS as a function of the total boron concentration: the lower the total boron concentration, the slower is the solid formation. The solid Eu(II) borate was characterized by IR spectroscopy, powder XRD and solid-state TRLFS. The determination of the europium to boron ratio portends the existence of pentaborate units in the amorphous solid.
\end{abstract}

\section{Introduction}

Actinides such as Am or Pu will define the long-term radiotoxicity of spent nuclear fuel. Therefore, nuclear waste has to be enclosed for a time period of up to $10^{6}$ years to protect the environment. There is worldwide consensus that nuclear waste repositories should be constructed in deep geological formations (salt, argillaceous rock, and granite) to store the waste.

Borates occur in significant amounts in such suitable geological formations, particularly in salt formations. For instance, the elemental analysis of brines of the WIPP site (Waste Isolation Pilot Plant near Carlsbad, New Mexico, USA) showed boron concentrations up to $160 \mathrm{mM} .^{1}$ Accordingly, this has to be expected in other salt-based repository formations, like in Germany, too. In salt-based geological formations boron compounds can occur dissolved in evaporite enclaves or as boron containing minerals, such as sassolite, borax, ulexite and colemanite. ${ }^{2}$ Furthermore, boron containing materials from nuclear technological processes stored in a nuclear waste repository will be not negligible and have to be considered. For instance, borosilicate glass coquilles in which

\footnotetext{
${ }^{a}$ Helmholtz-Zentrum Dresden-Rossendorf (HZDR), Institute of Resource Ecology, 01314 Dresden, Germany

${ }^{b}$ Technische Universität Dresden (TUD), Central Radionuclide Laboratory, 01062 Dresden, Germany.E-mail: margret.acker@tu-dresden.de

${ }^{c}$ University of Potsdam, Institute of Chemistry (Physical Chemistry), 14476 PotsdamGolm, Germany

${ }^{d}$ Technische Universität Dresden (TUD), Division of Radiochemistry and

Radioecology, 01062 Dresden, Germany

$\dagger$ Electronic supplementary information (ESI) available. See DOI: 10.1039/ c4dt00843j
}

the high-level radioactive waste is vitrified and containers for the direct storage of spent nuclear fuel which may carry the remains of boron that stems from the cooling water of the nuclear power plant will be part of the inventory of a nuclear waste repository.

One scenario to be evaluated within the safety and risk assessment of a nuclear waste repository is the contact of the repository inventory with water. Dissolution processes of the stored inventory (container material and radioactive waste) and host rock components are to be expected, followed by various physicochemical reactions of the mobilized species (complexation, sorption, formation of solid phases, etc.). These basic processes have to be understood in order to provide a stable and safe repository for nuclear waste over the time scale of $10^{6}$ years.

The corrosion of the waste containers during their storage in the repository for thousands of years could lead to the release of radionuclides and boron containing compounds. Corrosion processes are also estimated for the coquilles containing the vitrified radioactive waste. Due to the water-induced corrosion of the borosilicate glass matrix dissolved radionuclide species and locally high boron contents have to be considered.

Until now, the interactions of radionuclides, especially trivalent actinides, with boric acid and (poly)borates have been investigated only insufficiently.

Borkowski et al. were the first to investigate the complexation between $\mathrm{Nd}(\mathrm{III})$ as an analog for trivalent actinides (e.g., $\mathrm{Am}(\mathrm{III}), \mathrm{Pu}(\mathrm{III})$, and $\mathrm{Cm}(\mathrm{III}))$ and tetraborate under WIPP conditions. ${ }^{1}$ They found a $\mathrm{Nd}(\mathrm{III})$ borate complex $\left(\lg \beta_{11}=3 \ldots 4\right)$, which indicates that an accordant actinide(III) borate species could compete with the actinide carbonate complexation. ${ }^{1,3}$ In consequence, under WIPP conditions (up to $160 \mathrm{mM}$ borate, 
$\mathrm{pH}=8 \ldots 9$ ), this actinide(III) borate complex would be a predominant actinide species. ${ }^{1,3}$

Furthermore, synthetic solid actinide borate phases are known. For instance, Polinski et al. and Wang et al. synthesized different solid borates of trivalent actinides (and lanthanides) via hydrothermal syntheses. ${ }^{4-8}$ The obtained (poly)borates have complex structures, which depend strongly on the experimental conditions and the used metal.

However, more fundamental data are required for a better understanding of the actinide/lanthanide(III)- $\mathrm{B}(\mathrm{OH})_{3} /($ poly $)$ borate system.

This work introduces the results of the investigated europium (poly)borate complexation (similarly to neodymium, europium was used as a chemical analog for trivalent actinides) and provides evidence for a new europium solid phase in which (poly)borates are involved. The actinide/lanthanide(III) mobilization by (poly)borates will be discussed.

\section{Experimental}

\section{Chemicals and materials}

Chemicals of analytical grade and deionized water were used for the preparation of solutions. Boric acid (Merck), $\mathrm{B}(\mathrm{OH})_{3}$, was used to adjust the total boron concentration. All solution samples were prepared at $0.1 \mathrm{M}$ ionic strength $\left(\mathrm{NaClO}_{4}\right.$ (Merck)). A $0.03 \mathrm{M} \mathrm{Eu(III)} \mathrm{stock} \mathrm{solution} \mathrm{was} \mathrm{prepared} \mathrm{by} \mathrm{dis-}$ solving $\mathrm{Eu}_{2} \mathrm{O}_{3}$ (Aldrich) in $0.1 \mathrm{M} \mathrm{HClO}_{4}$. The pH measurements were carried out with a glass electrode, which was calibrated with buffer solutions (NIST/PTB standard buffers). The $\mathrm{pH}$ of the solutions was adjusted with $\mathrm{NaOH}$ or $\mathrm{HClO}_{4}$ (Merck). Elemental analyses were carried out with ICP-MS (Elan 9000, Perkin Elmer) and AAS (AAS-4100, Perkin Elmer). For the preparation of the solid $\mathrm{Eu}(\mathrm{III})$ borate (see below) $\mathrm{EuCl}_{3} \cdot 6 \mathrm{H}_{2} \mathrm{O}$ (Aldrich) was used.

\section{Boron speciation studies}

Samples with variable total boron concentrations (0.02 M-0.7 M) were prepared under ambient conditions $\left(T=22^{\circ} \mathrm{C}, p_{\mathrm{CO}_{2}}=\right.$ $\left.10^{-3.5} \mathrm{~atm}\right)$ at $\mathrm{pH} 5$ and $\mathrm{pH}$ 6. The high total boron concentrations (up to $0.7 \mathrm{M}$ ) were used to induce the formation of polyborates in appropriate amounts to influence the $\mathrm{Eu}(\mathrm{III})$ speciation investigated in subsequent complexation studies. After the dissolution of boric acid the samples were stored for four days to establish the boric acid/polyborate equilibrium. The samples were measured by means of ${ }^{11} \mathrm{~B}-\mathrm{NMR}$ spectroscopy.

\section{Eu(III) borate complexation studies}

Samples with variable total boron concentrations were prepared as described above at $\sim \mathrm{pH}$. Then $2 \mathrm{~mL}$ of the boron solution were transferred into a quartz cuvette and the $0.03 \mathrm{M}$ $\mathrm{Eu}(\mathrm{III})$ stock solution was added to adjust a total Eu(III) concentration of $3 \times 10^{-5} \mathrm{M}$. The samples were titrated at the same day (to exclude precipitation) from $\sim \mathrm{pH} 6$ down to $\sim \mathrm{pH} 2$ by adding appropriate amounts of $\mathrm{HClO}_{4}$. After each titration step a stationary europium luminescence spectrum was recorded.

\section{Eu(III) borate solid formation studies}

Samples with variable total boron concentrations were prepared as described above at $\mathrm{pH} 5$ and $\mathrm{pH}$. With the $0.03 \mathrm{M}$ $\mathrm{Eu}$ (III) stock solution a total Eu(III) concentration of $3 \times 10^{-5} \mathrm{M}$ was set. Directly after the addition of the Eu(III) stock solution and then during the next 427 days, stationary and timeresolved europium luminescence spectra were recorded for each sample. Membrane filtration $(1.2 \mu \mathrm{m}$ and $0.2 \mu \mathrm{m}$ pore size) of the samples and a subsequent determination of the europium content in the filtrates by ICP-MS were carried out to provide evidence of the solid formation.

\section{Synthesis of the Eu(III) borate solid}

A solution containing $0.7 \mathrm{M}$ total boron was prepared at $\mathrm{pH} 6$ as described above. Then solid $\mathrm{EuCl}_{3} \cdot 6 \mathrm{H}_{2} \mathrm{O}$ was added to adjust $10 \mathrm{mM}$ total Eu(III) concentration. A white solid precipitates rapidly. The solid was stored in its solution for three weeks and then separated from the liquid phase by centrifugation. The solid was washed several times with deionized water and then dried by lyophilization.

The ratio of europium, boron and sodium in the $\mathrm{Eu}(\mathrm{III})$ borate solid was determined by dissolving a defined amount of the solid in a defined volume of concentrated nitric acid and performing a subsequent analysis of the europium, boron and sodium content in this solution by ICP-MS (Eu, B) and AAS (Na). The sodium content was determined because there is evidence of a sodium pentaborate phase (see discussion of powder XRD results below) as a byproduct of the Eu(III) borate precipitation. In fact, an enhanced sodium content in the Eu(III) borate solid was detected.

\begin{abstract}
${ }^{11} \mathrm{~B}$ nuclear magnetic resonance spectroscopy $\left({ }^{11} \mathrm{~B}-\mathrm{NMR}\right)$
${ }^{11} \mathrm{~B}-\mathrm{NMR}$ spectra of boron containing solutions were recorded on a Varian Unity Inova 400 spectrometer with a field strength of $9.4 \mathrm{~T}$ and a corresponding ${ }^{11} \mathrm{~B}$ resonance frequency of 128.4 $\mathrm{MHz}$ with a $5 \mathrm{~mm}$ broadband probe. The ${ }^{11} \mathrm{~B}$ chemical shifts $(\delta)$ are referenced externally with respect to $\mathrm{BF}_{3}$ etherate in $\mathrm{CDCl}_{3}$. A $5 \mathrm{~mm} \mathrm{NMR}$ tube (quartz), containing the aqueous solution and $\mathrm{a}_{2} \mathrm{O}$ filled coaxial insert for deuterium lock, was used.
\end{abstract}

\section{Time-resolved laser-induced fluorescence spectroscopy (TRLFS)}

All measurements were carried out using a time gated detection mode to avoid contributions from strayed and scattered light and to resolve the temporal characteristics of the $\mathrm{Eu}$ luminescence.

Measurements of the europium containing solutions/suspensions were carried out with a Nd:YAG-OPO laser system (Continuum). Europium luminescence spectra of the stirred solutions/suspensions were recorded with a constant excitation wavelength of $394 \mathrm{~nm}$, a time window of $1 \mathrm{~ms}$, a pulse energy of 2-3 $\mathrm{mJ}$ and an optical multichannel analyzer (spectrograph 
(Oriel MS 257) and iCCD camera (Andor iStar)). Recording conditions for stationary spectra: wavelength range $565 \mathrm{~nm}-$ $650 \mathrm{~nm}, 1200$ line $\mathrm{mm}^{-1}$ grating, $0.2 \mathrm{~nm}$ resolution, 3000 accumulations. Recording conditions for time-resolved spectra: wavelength range $440 \mathrm{~nm}-780 \mathrm{~nm}, 300$ line $\mathrm{mm}^{-1}$ grating, $0.7 \mathrm{~nm}$ resolution, 100 accumulations, delay time steps $15 \mu \mathrm{s}-90 \mu \mathrm{s}$.

The solid-state TRLFS measurements at room temperature $\left(22^{\circ} \mathrm{C}\right)$ were performed using a Nd:YAG-OPO system as an excitation source (Nd:YAG: Quanta Ray, Spectra Physics; OPO: Flexi Scan, GWU-Lasertechnik) operated at $20 \mathrm{~Hz}$ repetition rate. The solid $\mathrm{Eu}(\mathrm{III})$ borate sample was placed in a self-made sample holder. The resulting luminescence emission was collected with a set of lenses and focused into a spectrograph (MS 257, LOT Oriel) equipped with an iCCD camera (iStar DH720, Andor Technology).

For the solid-state TRLFS measurements at low temperature $(T<5 \mathrm{~K})$ a solid $\mathrm{Eu}$ (III) borate sample was placed in a copper sample holder on top of a cooling head. The low temperature was achieved using a closed cycle helium cryostate (Helium compressor unit CKW-21, Sumitomo Heavy Industries Ltd; Turbolab 80, Oerlikon Leybold Vacuum; Model 331 Temperature Controller, Lakeshore). For exciting the $\mathrm{Eu}(\mathrm{III})$ via the ${ }^{5} \mathrm{D}_{0} \leftarrow{ }^{7} \mathrm{~F}_{0}$ transition a dye laser (Cobra Stretch, Sirah Laser- und Plasmatechnik) was used. Tuning the excitation wavelength in the spectral range $580 \mathrm{~nm} \pm 5 \mathrm{~nm}$ was possible with Pyrromethene 597 (Sirah Laser- und Plasamatechnik) as a laser dye, which was excited by the second harmonic output of a Nd:YAG laser (Quanta Ray, Spectra Physics) operating at a repetition rate of $10 \mathrm{~Hz}$ and a typical pulse length of $8 \mathrm{~ns}$. The excitation light was guided through an optical fiber to the $\mathrm{Eu}(\mathrm{III})$ sample. The emitted luminescence light was transferred through the same optical fiber to a spectrograph (Shamrock SR-303i, Andor Technology) attached to an iCCD camera (iStar DH 720, Andor Technology).

\section{Infrared spectroscopy (IR)}

FT-IR spectra were recorded on a Bruker Vertex 70v Fourier transform infrared spectrometer in the range $7500 \mathrm{~cm}^{-1}$ $370 \mathrm{~cm}^{-1}$ with a resolution of $4 \mathrm{~cm}^{-1}$. The samples were prepared as $\mathrm{KBr}$ pellets.

\section{Powder X-ray diffraction ( powder XRD)}

The experiments were performed at the PETRA III synchrotron radiation source at DESY Hamburg, Germany (High Resolution Powder Diffraction, P02.1). ${ }^{9}$ Synchrotron radiation with an energy of $60 \mathrm{keV}$ (corresponding to $\lambda=0.207 \AA$ ) was used. Diffraction patterns were collected in Debye-Scherrer-geometry with a PerkinElmer XRD 1621 area detector. The diffraction patterns were processed with the software FIT2D ${ }^{10}$ employing a $\mathrm{CeO}_{2}$ standard for calibration.

\section{Data analysis}

Different luminescence transition bands characterize the europium luminescence spectrum. In particular the ${ }^{5} \mathrm{D}_{0} \rightarrow{ }^{7} \mathrm{~F}_{0}$ (at $\sim 578 \mathrm{~nm}$; forbidden for the aquo ion $\mathrm{Eu}(\mathrm{III})_{\mathrm{aq}}$ ), ${ }^{5} \mathrm{D}_{0} \rightarrow{ }^{7} \mathrm{~F}_{1}$ (at $\sim 592 \mathrm{~nm}$ ) and ${ }^{5} \mathrm{D}_{0} \rightarrow{ }^{7} \mathrm{~F}_{2}$ (at $\sim 616 \mathrm{~nm}$ ) transition bands were analyzed. TRLFS spectra were analyzed with the software Origin $^{\mathrm{TM}}$ (version 7.5G, OriginLab Corporation). Stationary and time-resolved raw spectra were baseline corrected. Stationary luminescence spectra were normalized to the ${ }^{5} \mathrm{D}_{0} \rightarrow{ }^{7} \mathrm{~F}_{1}$ transition band because the luminescence to this transition is independent of the chemical environment of europium. ${ }^{11}$

The luminescence lifetimes were determined according to the exponential decay equation, eqn (1):

$$
I(t)=\sum_{i} I_{i} \exp \left(-t / \tau_{i}\right)
$$

(where $I(t)$ is the total luminescence intensity at time $t, I_{i}$ is the luminescence intensity of species $i$ at time $t=0$, and $\tau_{i}$ is the luminescence lifetime of species $i$ ).

Depending on the characteristics of the luminescence decay, monoexponential or biexponential decay equations (see eqn (1)) were used to fit the luminescence decay curves.

The luminescence lifetime $\tau$ of europium depends on the number of water molecules in the first coordination shell of europium. They act as luminescence quenchers. In general, their substitution by other ligands leads to an increase of the luminescence lifetime $\tau$, except for hydroxide ligands. The luminescence lifetime $\tau$ and the amount of water molecules in the first coordination shell of $\mathrm{Eu}(\mathrm{III})$ are correlated by an empirical equation, ${ }^{12,13}$ eqn (2):

$$
n_{\mathrm{H}_{2} \mathrm{O}} \pm 0.5=1.07 / \tau-0.62
$$

(where $n_{\mathrm{H}_{2} \mathrm{O}}$ is the amount of water molecules and $\tau$ is the luminescence lifetime in $\mathrm{ms}$ ).

From $n_{\mathrm{H}_{2} \mathrm{O}}$, further information about the chemical environment of europium is deducible. The luminescence lifetime $\tau$ of the europium aquo ion in water is specified with $110 \mu \mathrm{s} \pm 5 \mu \mathrm{s}$ corresponding to $8-9$ water molecules. ${ }^{14-16}$

Speciation calculations were carried out using the program HySS (Version 4.0.31). ${ }^{17}$

The complex formation constant and the single luminescence spectrum of the $\mathrm{Eu}(\mathrm{III})$ (poly)borate complex were determined with the calculation program HypSpec. ${ }^{18}$ The application of HypSpec has been demonstrated in several studies. ${ }^{19-22}$ The data set for the fitting procedure contained as parameters the model, total metal and ligand concentrations, $\mathrm{pH}$, protonation constant of the ligand, the measured europium luminescence spectra and the $\mathrm{Eu}(\mathrm{III})$ aquo ion luminescence spectrum as the known spectrum, respectively. Simplifications and approximations for the calculation of this complexation system are described in the section "Results and discussion".

Time-resolved emission (or luminescence) spectra of the $\mathrm{Eu}(\mathrm{III})$ borate complexation system and $\mathrm{Eu}(\mathrm{III})$ borate solid were analyzed by parallel factor analysis (PARAFAC), ${ }^{23}$ successfully applied before in a broad variety of research fields. ${ }^{24-26}$ 


\section{Results and discussion}

\section{Boron speciation in aqueous solution}

An understanding of the aqueous $\mathrm{B}(\mathrm{OH})_{3} /($ poly)borate speciation is an essential prerequisite to interpret the observed complexation and solid formation when europium is present in the borate system.

Boric acid, $\mathrm{B}(\mathrm{OH})_{3}$, is a weak acid with a high dissociation constant $\left(\mathrm{p} K_{\mathrm{a}}=8.98, I=0.1 \mathrm{M}\right)^{27}$ and acts as a Lewis acid (hydroxide acceptor), eqn (3):

$$
\mathrm{B}(\mathrm{OH})_{3}+\mathrm{H}_{2} \mathrm{O} \rightleftharpoons \mathrm{B}(\mathrm{OH})_{4}{ }^{-}+\mathrm{H}^{+}
$$

Above a total boron concentration of $25 \mathrm{mM}$ it forms polyborates in the $\mathrm{pH}$ range from 4 to $13 .^{28}$ This polymerization generates tri-, tetra- and pentaborates and even higher condensed species. ${ }^{27,29}$ In the past, efforts have been made to clarify this polymerization process by potentiometric titration, IR-, Raman- and NMR-spectroscopy, showing that the aqueous chemistry of boric acid is highly complex. ${ }^{27,28,30-38}$

Ingri et al. published formation constants for the polyborates $\mathrm{B}_{3} \mathrm{O}_{3}(\mathrm{OH})_{4}{ }^{-}, \quad \mathrm{B}_{5} \mathrm{O}_{6}(\mathrm{OH})_{4}{ }^{-}, \quad \mathrm{B}_{4} \mathrm{O}_{5}(\mathrm{OH})_{4}{ }^{2-}$ and $\mathrm{B}_{3} \mathrm{O}_{3}{ }^{-}$ $(\mathrm{OH})_{5}{ }^{2-} \cdot{ }^{27,28,31}$ With these data a $\mathrm{B}(\mathrm{OH})_{3}$-polyborate speciation can be calculated. A speciation diagram is shown for the $\mathrm{pH}$ range 0 to 14 and a total boron concentration of $c_{\mathrm{B}, \text { total }}=0.7 \mathrm{M}$ (Fig. 1).

Up to $\mathrm{pH} 6$ (the investigated $\mathrm{pH}$ range of this work), only the boron species $\mathrm{B}(\mathrm{OH})_{3}, \quad \mathrm{~B}_{3} \mathrm{O}_{3}(\mathrm{OH})_{4}{ }^{-}$(triborate) and $\mathrm{B}_{5} \mathrm{O}_{6}(\mathrm{OH})_{4}{ }^{-}$(pentaborate) are expected to be present in solution. The calculated distribution of $\mathrm{B}_{3} \mathrm{O}_{3}(\mathrm{OH})_{4}{ }^{-}$and $\mathrm{B}_{5} \mathrm{O}_{6}(\mathrm{OH})_{4}{ }^{-}$with the data of Ingri et al. ${ }^{27,28,31}$ as a function of $c_{\mathrm{B}, \text { total }}$ and $\mathrm{pH}$ is shown in Fig. 2 .

The polyborate species $\mathrm{B}_{3} \mathrm{O}_{3}(\mathrm{OH})_{4}{ }^{-}$and $\mathrm{B}_{5} \mathrm{O}_{6}(\mathrm{OH})_{4}{ }^{-}$appear in significant amounts at higher $c_{\mathrm{B} \text {,total }}$ between $\mathrm{pH} 4$ and $\mathrm{pH}$ 5. At $\mathrm{pH} 6$ and $c_{\mathrm{B} \text {,total }}=0.7 \mathrm{M}$ these polyborate species represent around $3.5 \%$ of the total boron speciation. This corresponds to a maximum polyborate concentration of $\sim 0.025 \mathrm{M}$.

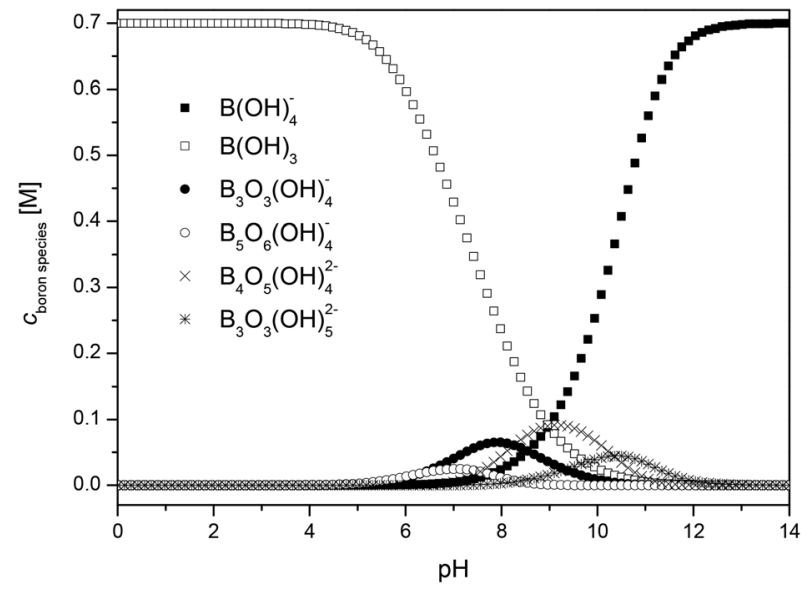

Fig. $1 \mathrm{~B}(\mathrm{OH})_{3}$-polyborate speciation for $c_{\mathrm{B} \text {, total }}=0.7 \mathrm{M}, I=0.1 \mathrm{M}$.

${ }^{11} \mathrm{~B}-\mathrm{NMR}$ is well applicable to identify boron species in aqueous solution. ${ }^{32}$ Borates consist of at least one tetra-coordinated (tetrahedral) boron center $\left[\mathrm{BO}_{4}\right]$ and tri-coordinated (trigonal planar) boron centers $\left[\mathrm{BO}_{3}\right]$ (number depending on the (poly)borate species). Since the nucleus is sensitive to its local electronic environment, the boron atoms in $\left[\mathrm{BO}_{3}\right]$ and $\left[\mathrm{BO}_{4}\right]$ can easily be distinguished by their well separated NMR signals. Due to the higher coordination and, thus, negative charge, the $\left[\mathrm{BO}_{4}\right]$ boron nucleus is more shielded by the increased electronic density as compared to the $\left[\mathrm{BO}_{3}\right]$ boron nucleus. Its ${ }^{11} \mathrm{~B}$ chemical shift occurs around $1 \mathrm{ppm}$ (for instance observable for $\left.\mathrm{B}(\mathrm{OH})_{4}{ }^{-}\right),{ }^{32}$ whereas the NMR signal of $\left[\mathrm{BO}_{3}\right]$, like in $\mathrm{B}(\mathrm{OH})_{3}$, occurs around $19 \mathrm{ppm}{ }^{32}$ As $\left[\mathrm{BO}_{4}\right]$ possesses a spherical and more symmetric electronic environment, the signal is quite narrow. Because of the non-spherical electronic environment around $\left[\mathrm{BO}_{3}\right]$, the resulting electric field gradient causes a fast relaxation of the boron nucleus being quadrupolar. This leads to a considerable line broadening.
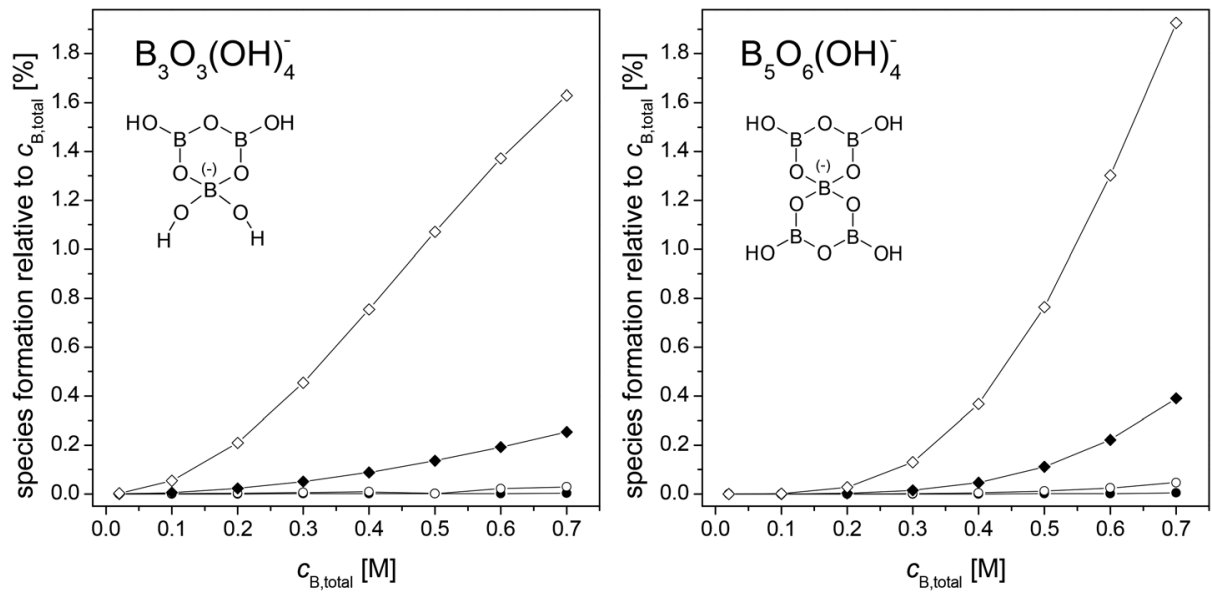

$-\mathrm{pH} 3-\circ \mathrm{pH} 4 \prec \mathrm{pH} 5 \multimap \mathrm{pH} 6$

Fig. 2 Distribution of different borate species as a function of $c_{B, \text { total }}$ and $\mathrm{pH}, I=0.1 \mathrm{M}$. 


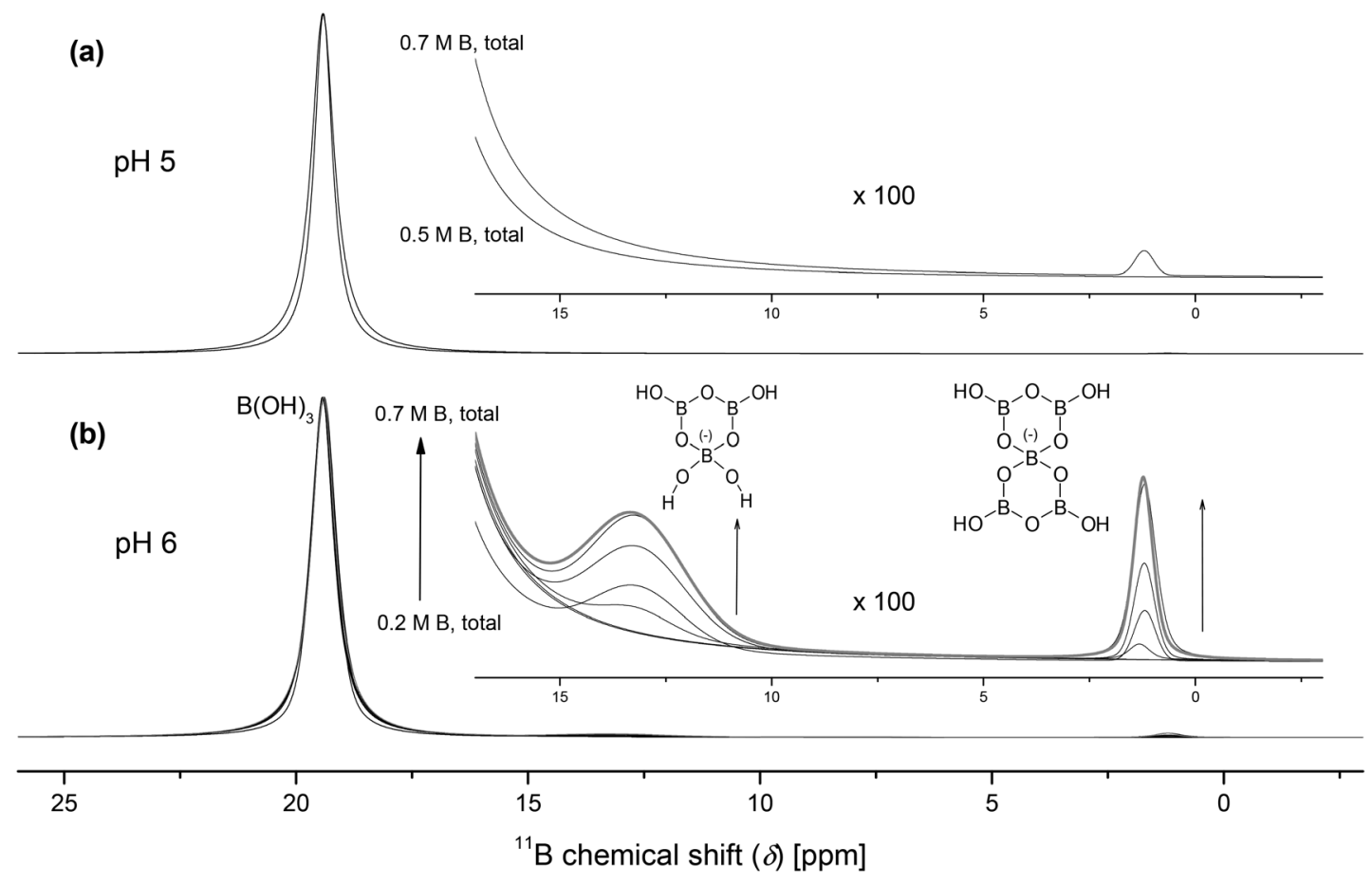

Fig. $3{ }^{11} \mathrm{~B}-\mathrm{NMR}$ spectra (normalized) of solutions containing variable amounts of total boron (0.2 $\mathrm{M}$ to $0.7 \mathrm{M}$, step size $0.1 \mathrm{M}$ ) (a) at pH 5 and (b) at $\mathrm{pH} 6$; in each case $I=0.1 \mathrm{M}$. The insets show expansion of the polyborate region. The ${ }^{11} \mathrm{~B}-\mathrm{NMR}$ spectrum in grey shows a six months aged solution containing $0.7 \mathrm{M}$ total boron concentration at $\mathrm{pH} 6, I=0.1 \mathrm{M}$.

In the case of the pentaborate (at $\delta=1.2 \mathrm{ppm}$; signal assignment according to Hertam et al. $^{32}$ ) these effects may disallow the observation of the $\left[\mathrm{BO}_{3}\right]$ signal. Otherwise the $\left[\mathrm{BO}_{3}\right]$ signal of the pentaborate could be overlapped by the huge signal of $\mathrm{B}(\mathrm{OH})_{3}$. The $\left[\mathrm{BO}_{4}\right]$ unit of the pentaborate is fixed by the molecular structure. This results in NMR signal properties, i.e., chemical shift and line width, quite similar to that of the monoborate anion. To interpret the position of the NMR signal of the triborate species (at $\delta=13 \mathrm{ppm}$; signal assignment according to Hertam et $a .^{32}$ ) an intramolecular $\mathrm{OH}$ group transfer (site exchange between $\left[\mathrm{BO}_{3}\right]$ and $\left[\mathrm{BO}_{4}\right]$ ) has to be considered. This causes a broad signal at the population-weighted average chemical shift of the nuclei in the two sites.

At pH 5 and up to $0.5 \mathrm{M}$ total boron concentration no polyborate species were detected by ${ }^{11} \mathrm{~B}$-NMR (Fig. 3a). The only boron species found was the undissociated boric acid at $\delta=$ $19.4 \mathrm{ppm}$. Above $0.5 \mathrm{M} \mathrm{B}(\mathrm{OH})_{3}$ small amounts of polyborates occur. At pH 6 and total boron concentrations $>0.4 \mathrm{M}$ three boron species can be observed (Fig. 3b). The described signals at $\delta=19.4 \mathrm{ppm}, 13.3 \mathrm{ppm}$ and $1.2 \mathrm{ppm}$ (see above) are assigned to boric acid $\mathrm{B}(\mathrm{OH})_{3}$, the triborate species $\mathrm{B}_{3} \mathrm{O}_{3}(\mathrm{OH})_{4}{ }^{-}$and the pentaborate species $\mathrm{B}_{5} \mathrm{O}_{6}(\mathrm{OH})_{4}{ }^{-}$, respectively. With increasing total boron concentration the amount of these polyborate species increased. Besides the described species, no further polyborates were formed. Moreover, a sample with a content of $0.7 \mathrm{M}$ total boron aged for six months showed no differences in the ${ }^{11} \mathrm{~B}$-NMR spectrum com- pared to a freshly prepared one (Fig. $3 \mathrm{~b}$ ). Thus, the $\mathrm{B}(\mathrm{OH})_{3}{ }^{-}$ (poly)borate speciation remained stable.

$\mathrm{Eu}(\mathrm{III})$ speciation in the absence and presence of boron species $\left(\mathrm{B}(\mathrm{OH})_{3}\right.$, (poly)borates)

The experiments of this work were carried out in the acidic $\mathrm{pH}$ range to make the complexation studies in the $\mathrm{Eu}(\mathrm{III})-\mathrm{B}(\mathrm{OH})_{3} /$ (poly)borate system less difficult. Under these conditions strong Eu(III) hydroxo (carbonato) complexes as well as the formation of solid $\mathrm{Eu}$ (III) hydroxides (and carbonates) can be excluded. In the absence of boron species the $\mathrm{Eu}(\mathrm{III})$ speciation up to pH 6 is exclusively dominated by the Eu(III) aquo ion $\left(\mathrm{Eu}(\mathrm{III})_{\mathrm{aq}}\right)$. Hydrolysis of $\mathrm{Eu}(\mathrm{III})$ and the reaction with carbonate at $\mathrm{pH}<6$ are still negligible (at most $1 \%$ of the total europium). Furthermore, the polyborate equilibrium is still complex in the acidic $\mathrm{pH}$ range but simpler than in the alkaline $\mathrm{pH}$ range (Fig. 1 and 2).

The $\mathrm{Eu}(\mathrm{III})$ speciation in aqueous solution can be investigated with high selectivity and sensitivity using the timeresolved laser-induced fluorescence spectroscopy (TRLFS). In the presence of boron $\left(c_{\mathrm{B}, \text { total }}=0 \ldots 0.7 \mathrm{M}\right)$ at $\mathrm{pH} 6$ stationary and time-resolved luminescence spectra of $\mathrm{Eu}(\mathrm{III})$ were measured. With increasing total boron concentration, changes in the europium luminescence spectra and emission lifetimes $\tau$ occurred. The intensities of the ${ }^{5} \mathrm{D}_{0} \rightarrow{ }^{7} \mathrm{~F}_{0}$ and ${ }^{5} \mathrm{D}_{0} \rightarrow{ }^{7} \mathrm{~F}_{2}$ luminescence bands increased, pointing to a reduced overall symmetry of the Eu(III) complex(es) in comparison with the $\mathrm{Eu}(\mathrm{III})_{\mathrm{aq}}$ (Fig. 4a). The luminescence lifetime $\tau$ of europium 

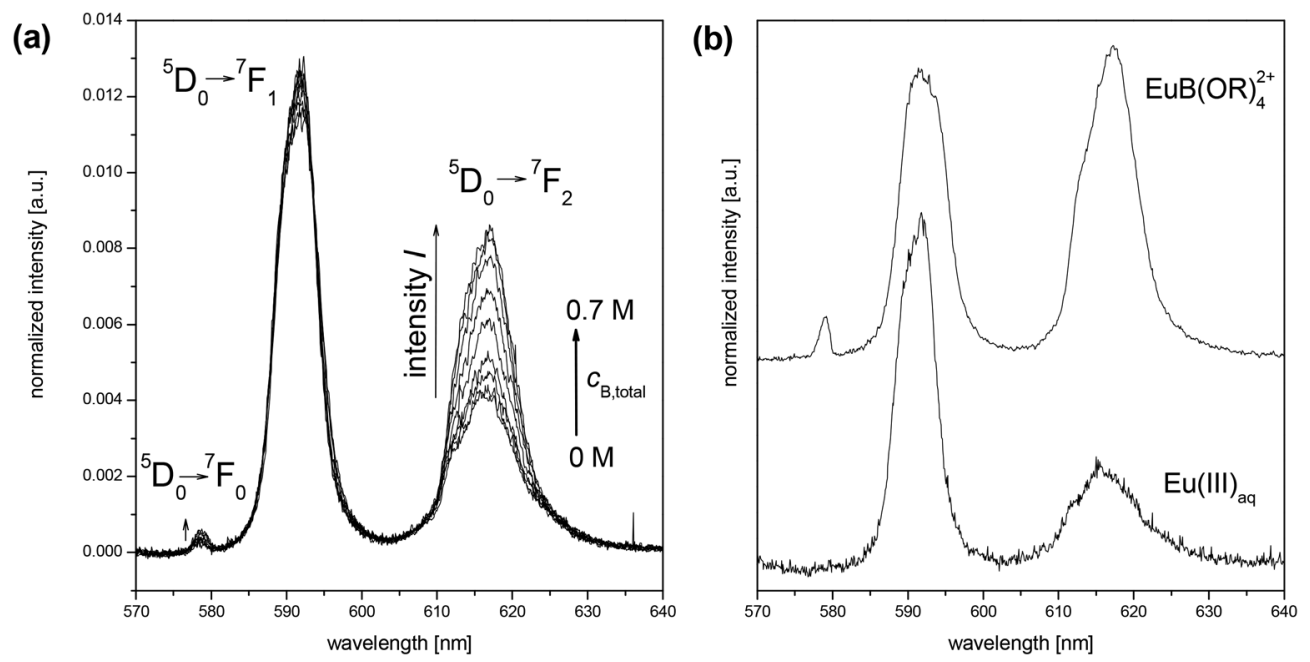

Fig. 4 (a) Europium luminescence spectra at $\mathrm{pH} 6$ as a function of $c_{\mathrm{B}, \text { total }}, 3 \times 10^{-5} \mathrm{M} \mathrm{Eu(III),} I=0.1 \mathrm{M}$; (b) single spectra of Eu(III) aq $(\mathrm{measured})$ and the Eu(III) borate complex, EuB(OR) ${ }_{4}^{2+}$ (calculated by HypSpec; ${ }^{18} \mathrm{R}=\mathrm{H}$ and/or $\left[\mathrm{BO}_{3}\right]$ units).

Table 1 Europium luminescence parameters (emission lifetime $\tau, n_{\mathrm{H}_{2} \mathrm{O}}$ ) at $\mathrm{pH} 6$ as a function of $c_{\mathrm{B} \text {, total }}$

\begin{tabular}{lll}
\hline$c_{\mathrm{B}, \text { total }}[\mathrm{M}]$ & $\tau[\mu \mathrm{s}]$ & $n_{\mathrm{H}_{2} \mathrm{O}}$ \\
\hline 0 & $113.0 \pm 1.0$ & $8-9$ \\
0.02 & $113.5 \pm 0.9$ & $8-9$ \\
0.1 & $113.4 \pm 0.8$ & $8-9$ \\
0.2 & $115.0 \pm 1.0$ & $8-9$ \\
0.3 & $120.1 \pm 0.5$ & $8-9$ \\
0.4 & $126.8 \pm 0.7$ & $7-8$ \\
0.5 & $134.5 \pm 0.6$ & $7-8$ \\
0.6 & $142.9 \pm 0.6$ & $6-7$ \\
0.7 & $149.4 \pm 0.7$ & $6-7$
\end{tabular}

rises up to $\sim 150 \mu \mathrm{s}$ at the highest investigated total boron concentration $(0.7 \mathrm{M})$, which corresponds to a removal of 2-3 water molecules from the first coordination shell of europium (Table 1).

These findings clearly show a europium complexation by the in solution existing boron species. Up to a total boron concentration of $\sim 0.1 \mathrm{M}$, where no or almost none polyborates exist, no changes in the luminescence parameters of europium in comparison with $\mathrm{Eu}(\mathrm{III})_{\mathrm{aq}}$ occurred. Hence, boric acid forms no complexes with europium. At higher total boron concentrations polyborates occur and concurrently changes in the luminescence parameters of europium were observed. Obviously, an interaction between polyborates and $\mathrm{Eu}(\mathrm{III})$ occurs which influences the Eu(III) speciation.

Additionally, the influence of polyborates was investigated for different total boron concentrations as a function of $\mathrm{pH}$. For illustration the $\mathrm{F}_{1} / \mathrm{F}_{2}$ ratio (intensity ratio of the ${ }^{5} \mathrm{D}_{0} \rightarrow{ }^{7} \mathrm{~F}_{1}$ and ${ }^{5} \mathrm{D}_{0} \rightarrow{ }^{7} \mathrm{~F}_{2}$ luminescence bands) is plotted against $\mathrm{pH}$ (Fig. 5).

The Eu(III) polyborate complexation was observed in the $\mathrm{pH}$ range $\sim 4.2$ to 6 (highest investigated $\mathrm{pH}$ ) at the highest investigated total boron concentration $(0.7 \mathrm{M})$. Below $\mathrm{pH} \sim 4.2$, the polyborate concentration is too low to influence the europium

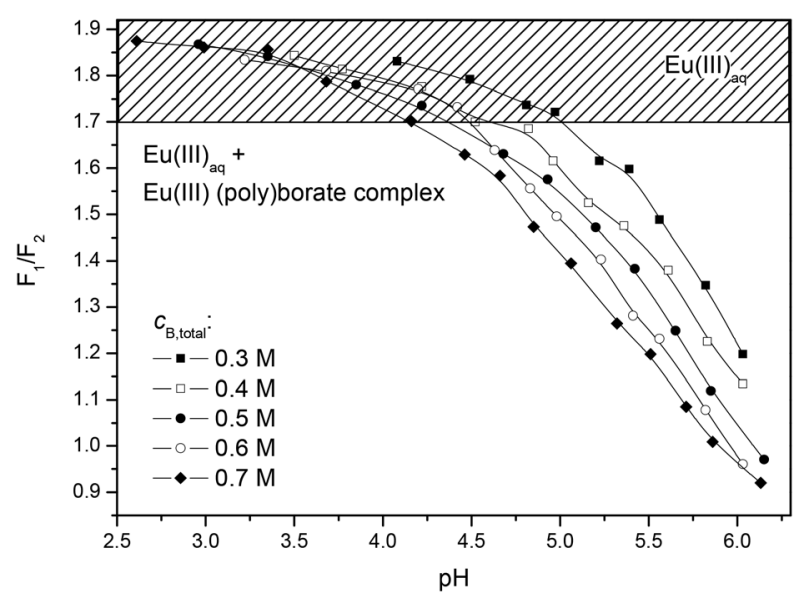

Fig. $5 \mathrm{~F}_{1} / \mathrm{F}_{2}$ ratios from TRLFS $\mathrm{pH}$ titration of solutions containing $3 \times 10^{-5} \mathrm{M} \mathrm{Eu}(\mathrm{II})$ and variable $c_{\mathrm{B}, \text { total }}, I=0.1 \mathrm{M}$.

speciation. This is in good agreement with the calculated boron speciation (Fig. 2).

We tried to determine a complexation constant of the Eu(III) borate species from the TRLFS $\mathrm{pH}$ titration of solutions containing $\mathrm{Eu}(\mathrm{III})$ and variable amounts of total boron (Fig. 5). This, however, proved to be difficult, because several polyborates coexist. The separation of their complexes with europium was not possible.

Therefore, a simpler model was used at least to estimate the order of magnitude of the Eu(III) (poly)borate complexation constant. It was assumed that all polyborate species with the structural unit " $\mathrm{B}(\mathrm{OR})_{4}{ }^{-"}$ " $\left(\mathrm{R}=\mathrm{H}\right.$ and/or $\left[\mathrm{BO}_{3}\right]$ units $)$ show similar complexation properties with similar values for the complexation constants. Therefore, a model species " $\mathrm{B}(\mathrm{OR})_{4}{ }^{- \text {" }}$ was used for the estimation.

The PARAFAC of the time-resolved europium spectra as a function of $c_{\mathrm{B} \text {,total }}$ (Table 1) showed that until $0.7 \mathrm{M}$ total boron concentration, only the $\mathrm{Eu}(\mathrm{III})_{\mathrm{aq}}$ and one europium 
Table 2 Calculated $\lg \beta_{11}$ values for different data sets and averaged value for $\lg \beta_{11}$ of the $\mathrm{Eu}(\mathrm{III})$ borate complex, $\mathrm{EuB}(\mathrm{OR})_{4}{ }^{2+}, \mathrm{C}_{\mathrm{Eu}(\mathrm{III})}=3 \times 10^{-5} \mathrm{M}$, $I=0.1 \mathrm{M}, T=22^{\circ} \mathrm{C}$

\begin{tabular}{lll}
\hline Data set & $c_{\mathrm{B}, \text { total }}[\mathrm{M}]$ & $\lg \beta_{11}$ \\
\hline 1 & 0.4 & 2.29 \\
2 & 0.5 & 2.13 \\
3 & 0.5 & 2.05 \\
4 & 0.6 & 1.97 \\
5 & 0.6 & 2.03 \\
6 & 0.7 & 1.83 \\
7 & 0.7 & 1.83 \\
& & $2.02 \pm 0.33(2 \sigma)$ (averaged value)
\end{tabular}

complex are existent. Therefore, only the 1:1 Eu(III) borate complex, $\operatorname{EuB}(\mathrm{OR})_{4}{ }^{2+}$, has to be considered in the calculations. The complexation constant for this complex is expressed in eqn (4):

$$
\lg \beta_{11}=\frac{\left[\mathrm{EuB}(\mathrm{OR})_{4}{ }^{2+}\right]}{\left[\mathrm{Eu}^{3+}\right]\left[\mathrm{B}(\mathrm{OR})_{4}{ }^{-}\right]}
$$

The equilibrium concentration of the model species " $\mathrm{B}(\mathrm{OR})_{4}{ }^{- \text {" }}$ is the sum of the equilibrium concentrations of the (poly)borate species. This sum was calculated from the speciation data of Ingri et al. ${ }^{27,28,31}$

The analyses of the titration data corresponding to different total boron concentrations using the concentration of the model species " $\mathrm{B}(\mathrm{OR})_{4}{ }^{-}$" as a function of the $\mathrm{pH}$ yielded the complexation constants for the $\mathrm{Eu}(\mathrm{III})$ borate complex, $\mathrm{EuB}(\mathrm{OR})_{4}{ }^{2+}$ (Table 2).

For the $\operatorname{EuB}(\mathrm{OR})_{4}{ }^{2+}$ complex an averaged value of $\lg \beta_{11}=2$ was estimated. This value illustrates the order of magnitude of $\mathrm{Eu}(\mathrm{III})$ (poly)borate complexes and shows that these complexes are quite weak. The single spectrum of the $\operatorname{EuB}(\mathrm{OR})_{4}{ }^{2+}$ complex extracted from the measured sum spectra is shown in Fig. $4 \mathrm{~b}$.

To the best of our knowledge there is only one publication declaring a $\operatorname{Ln}(\mathrm{III})$ borate complexation constant. Borkowski et al. determined in their pioneering work a complexation constant for a $\mathrm{Nd}(\mathrm{III})$ tetraborate complex with $\lg \beta_{11} \sim 3 \ldots 4$ as a function of ionic strength. ${ }^{1}$ This constant differs from the result of this work, which might be due to different reasons.

Borkowski et al. determined the complexation constant at about $\mathrm{pH} 8.6$ by solubility experiments. The tetraborate species, which was the supposed complexing agent in their work, has two binding sites to interact with the metal ion. Therefore, the $\operatorname{Ln}(\mathrm{III})$ complex with tetraborate is probably stronger than the complexes with polyborates containing only one binding site, as investigated in this work. Additionally, Ln(III) hydroxoborate species could exist under alkaline conditions. For instance, in the inorganic $\mathrm{Cm}(\mathrm{III})-\mathrm{NO}_{3}$ system ternary $\mathrm{Cm}(\mathrm{III})-\mathrm{OH}-\mathrm{NO}_{3}$ species were found under alkaline conditions. ${ }^{39}$ It is imaginable that the attachment of hydroxo ligands onto the metal borate complex strengthens the Ln/An(III) complexation.

Independent of the previous discussion there is a need for clarification of the supposed borate speciation published by
Borkowski and co-workers. $\mathrm{Na}_{2} \mathrm{~B}_{4} \mathrm{O}_{7} \cdot 10 \mathrm{H}_{2} \mathrm{O}$ was used in their work to prepare tetraborate containing solutions. But it is known that $\mathrm{Na}_{2} \mathrm{~B}_{4} \mathrm{O}_{7}$ is not stable in aqueous solution and dissociates into $\mathrm{B}(\mathrm{OH})_{3} / \mathrm{B}(\mathrm{OH})_{4}{ }^{-}$. From boric acid a new polyborate equilibrium with further polyborates is regulated. Therefore, the borate speciation would involve more complexes than the supposed tetraborate species. Even if the polyborate concentration is low, due to the dissociation of the tetraborate molecule more complexing borate molecules $\left(\mathrm{B}(\mathrm{OH})_{4}{ }^{-}\right)$are generated than expected. This would lead to an underestimation of the effective borate concentration in their experiments. Therefore, the complexation constant for a $\mathrm{Nd}$ (III) borate would be smaller than the reported one.

Furthermore, Hinz et al. carried out solubility experiments under the same conditions. A clear solubility decrease of $\mathrm{Nd}$ (III) in the presence of borate was determined. ${ }^{40}$ This is contradictory to the results of Borkowski et al. and indicates the formation of a further solid phase in which borates are involved. Therefore, the An/Ln(III)-borate system is much more difficult under alkaline conditions and a multitude of reactions occur which are not clear and actually not manageable for complexation studies.

The investigations of this work were carried out under acidic conditions. Strongly competing reactions (for instance hydrolysis of Eu(III)) can be excluded. The calculation of the equilibrium (poly)borate concentrations under acidic conditions is more reliable, because the amount of different polyborate species is reduced. The used TRLFS is a species sensitive method that allows us to observe the europium (poly)borate species even in the presence of only small amounts of complexing (poly)borates in the investigated $\mathrm{pH}$ range. Because the complexed europium species was observed directly by spectroscopy the derived complexation constant for the Eu(III)-(poly)borate complex seems to be reliable.

Nevertheless, the work of Borkowski et al. demonstrates the importance of studying the actinide-borate system, because borate compounds are not negligible in a nuclear waste repository.

\section{Formation of a $\mathrm{Eu}(\mathrm{III})$ borate solid species in aqueous solution}

Europium and boron containing solutions at $\mathrm{pH} 5$ and $\mathrm{pH} 6$ (see the Experimental section) were investigated by TRLFS as well as membrane filtration and subsequent determination of the europium content in the filtrates using ICP-MS.

Some days after the preparation of the boron and europium containing solutions at $\mathrm{pH} 6$ remarkable changes in the europium luminescence spectra and lifetimes $\tau$ were observed in some samples. In these spectra the luminescence bands were characteristically split (Fig. 6a) and the luminescence lifetimes $\tau$ distinctly increased (Fig. 6b) in comparison with the luminescence spectra and lifetimes measured directly after the sample preparation. These changes indicate the formation of a new europium species. In contrast, in the same investigation period at $\mathrm{pH} 5$ no changes in the europium emission spectra and lifetimes of freshly prepared samples in comparison with the aged samples were observed. 

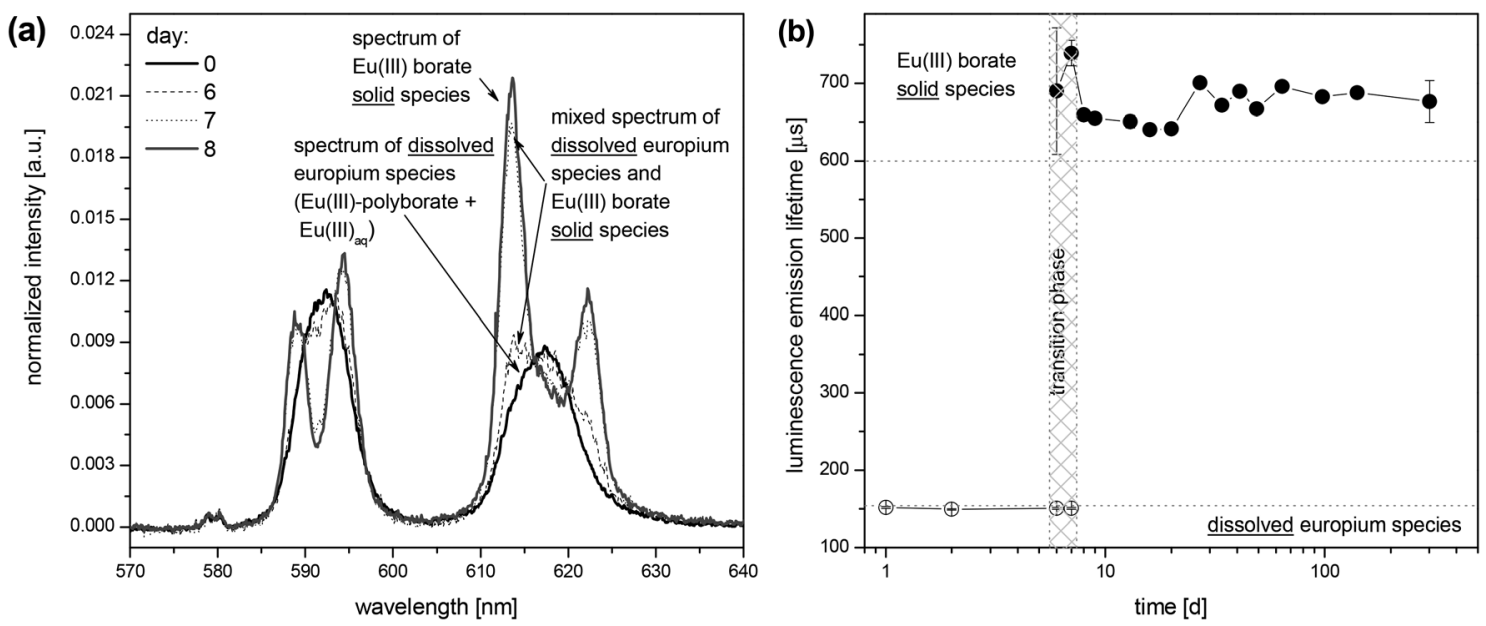

Fig. 6 (a) Formation progress of the Eu(III) borate solid species for a solution containing $3 \times 10^{-5} \mathrm{M} \mathrm{Eu(III),} C_{B, \text { total }}=0.7 \mathrm{M}, I=0.1 \mathrm{M}$ at pH 6 ; (b) luminescence lifetime $\tau$ of europium observed with time.

Membrane filtrations of the europium and boron containing solutions at $\mathrm{pH} 5$ and $\mathrm{pH} 6$ through different pore sizes were carried out. The investigation of the filtrates of the solutions with the characteristically split europium luminescence spectra by ICP-MS showed a removal of europium. Therefore, the formation of a solid species can be demonstrated. In solutions at pH 6 with low total boron concentrations $(<0.3 \mathrm{M})$ and pH 5 with variable total boron concentrations up to $0.7 \mathrm{M}$ no formation of a solid species was detectable by membrane filtration and subsequent determination of the europium content in the filtrates using ICP-MS.

No other europium solids (hydroxides, carbonates, hydroxycarbonates) are thermodynamically stable under the used experimental conditions; thus, the observed solid must be a solid Eu(III) borate species. The described Eu(III) (poly)borate complex (see above) is supposed to be the precursor of this solid. In solutions at $\mathrm{pH} 5$ with variable total boron concentrations up to $0.7 \mathrm{M}$ and $\mathrm{pH} 6$ with low total boron concentrations $(<0.3 \mathrm{M})$ no precipitations were observed. This indicates that the concentration of the polyborates and, therefore, the amount of the $\mathrm{Eu}(\mathrm{III})$ polyborate complex is too low to induce the $\mathrm{Eu}(\mathrm{III})$ borate precipitation.

The progress of the solid formation of the $\mathrm{Eu}(\mathrm{III})$ borate was investigated by TRLFS in solutions containing $3 \times 10^{-5} \mathrm{M}$ $\mathrm{Eu}(\mathrm{III})$ and variable concentrations of total boron $(0.2 \mathrm{M} . .0 .7 \mathrm{M})$ at $\mathrm{pH}$ 6. A splitting of the luminescence bands corresponding to the ${ }^{5} \mathrm{D}_{0} \rightarrow{ }^{7} \mathrm{~F}_{1}$ and ${ }^{5} \mathrm{D}_{0} \rightarrow{ }^{7} \mathrm{~F}_{2}$ transitions during the formation progress of the solid species occurred till a spectrum characteristic of the $\mathrm{Eu}(\mathrm{III})$ borate solid was reached (Fig. 6a). In the transition phase (see Fig. 6b) a biexponential luminescence decay curve was determined. A short luminescence lifetime $(120 \mu \mathrm{s} . .$. $150 \mu \mathrm{s})$ for the dissolved $\mathrm{Eu}(\mathrm{III})$ species and a long lifetime $(600 \mu \mathrm{s} . . .700 \mu \mathrm{s})$ for the solid $\mathrm{Eu}(\mathrm{III})$ species were identified (Fig. 6b, Fig. S1, S2 $\dagger$ ). After a certain time, depending on the total boron concentration, only the long europium luminescence lifetime $\tau(600 \mu \mathrm{s} . . .700 \mu \mathrm{s})$ attributed to the Eu(III) borate solid species was observed. It shows the complete formation of the solid, Fig. S1. $\dagger$ The solid Eu(III) borate seems to be stable over a long time. The long lifetime of $600 \mu \mathrm{s}-700 \mu \mathrm{s}$ characteristic of this europium solid was determined even after 1.5 years, Fig. $\mathrm{S} 2 . \dagger$

It was shown that the lower the total boron concentration, the slower is the formation of the solid species (Fig. S2 $\uparrow$ ). At $0.7 \mathrm{M}$ total boron concentration the solid formation starts much earlier (between 2 and 6 days) than at $0.4 \mathrm{M}$ total boron concentration (between 98 and 141 days). The solid formation was detected for total boron concentrations $\geq 0.3 \mathrm{M}$. Below that concentration the amount of the dissolved $\mathrm{Eu}(\mathrm{III})$ polyborate complex is too low to induce the precipitation of the solid, at least within the investigated time of 1.5 years.

The $\mathrm{B}(\mathrm{OH})_{3}$-polyborate equilibrium is dynamic. If polyborates of the aqueous phase are removed from the equilibrium due to the $\mathrm{Eu}$ (III) borate solid formation there is still a sufficient amount of boric acid in solution to regulate the $\mathrm{B}(\mathrm{OH})_{3}$-polyborate equilibrium. Thus, the dissolved $\mathrm{Eu}(\mathrm{III})$ is almost completely converted into the solid if enough polyborate species are reproduced. This was verified by the quantitative analysis of europium in the filtrates (see above).

\section{Characterization of the solid Eu(III) borate}

Powder XRD. Powder diffraction measurements indicated that the precipitated $\mathrm{Eu}(\mathrm{III})$ borate consists of an amorphous phase. Weak reflections cannot be brought into agreement with known solid structures of europium borates. There are indications of a minor crystalline sodium pentaborate phase $\left(\mathrm{Na}_{2}\left[\mathrm{~B}_{5} \mathrm{O}_{8}(\mathrm{OH})\right] \cdot \mathrm{H}_{2} \mathrm{O}\right),{ }^{41}$ which was co-precipitated with the $\mathrm{Eu}(\mathrm{III})$ borate (Fig. S3†).

IR. The IR spectrum of the $\mathrm{Eu}(\mathrm{III})$ borate solid is clearly different from that of boric acid (one of the reactants for the $\mathrm{Eu}(\mathrm{III})$ borate solid synthesis). Boric acid as a representative of compounds with exclusively trigonal planar boron centers $\left[\mathrm{BO}_{3}\right]$ showed characteristic vibration bands in the wavenumber range $4000 \mathrm{~cm}^{-1}-380 \mathrm{~cm}^{-1}$ (Fig. 7a, Table 3). These bands can be assigned to well-known vibrations of the boric acid. ${ }^{42-45}$ 

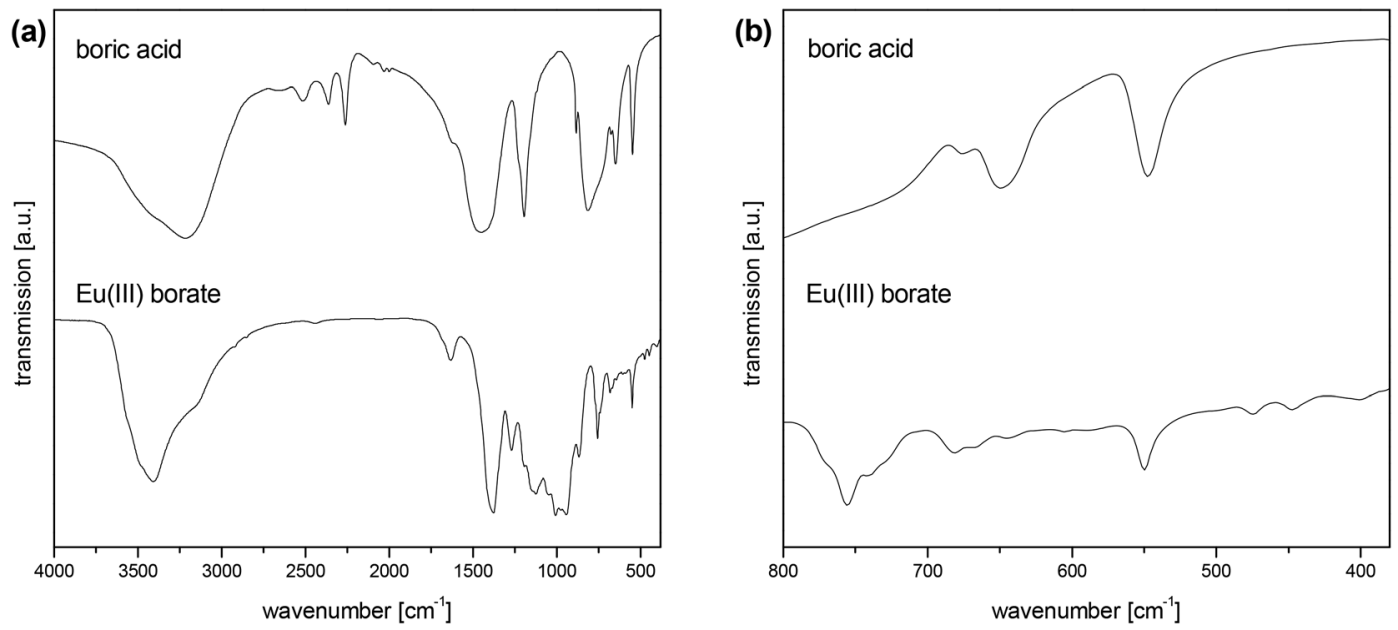

Fig. 7 IR spectrum of the solid Eu(III) borate (below) and for comparison of boric acid (top) in the range of (a) $4000 \mathrm{~cm}^{-1}$ to $380 \mathrm{~cm}^{-1}$ and (b) $700 \mathrm{~cm}^{-1}$ to $480 \mathrm{~cm}^{-1}$ (range of characteristic pulse vibrations of polyborates).

Table 3 Observed frequencies in the IR spectra of boric acid and the solid Eu(III) borate

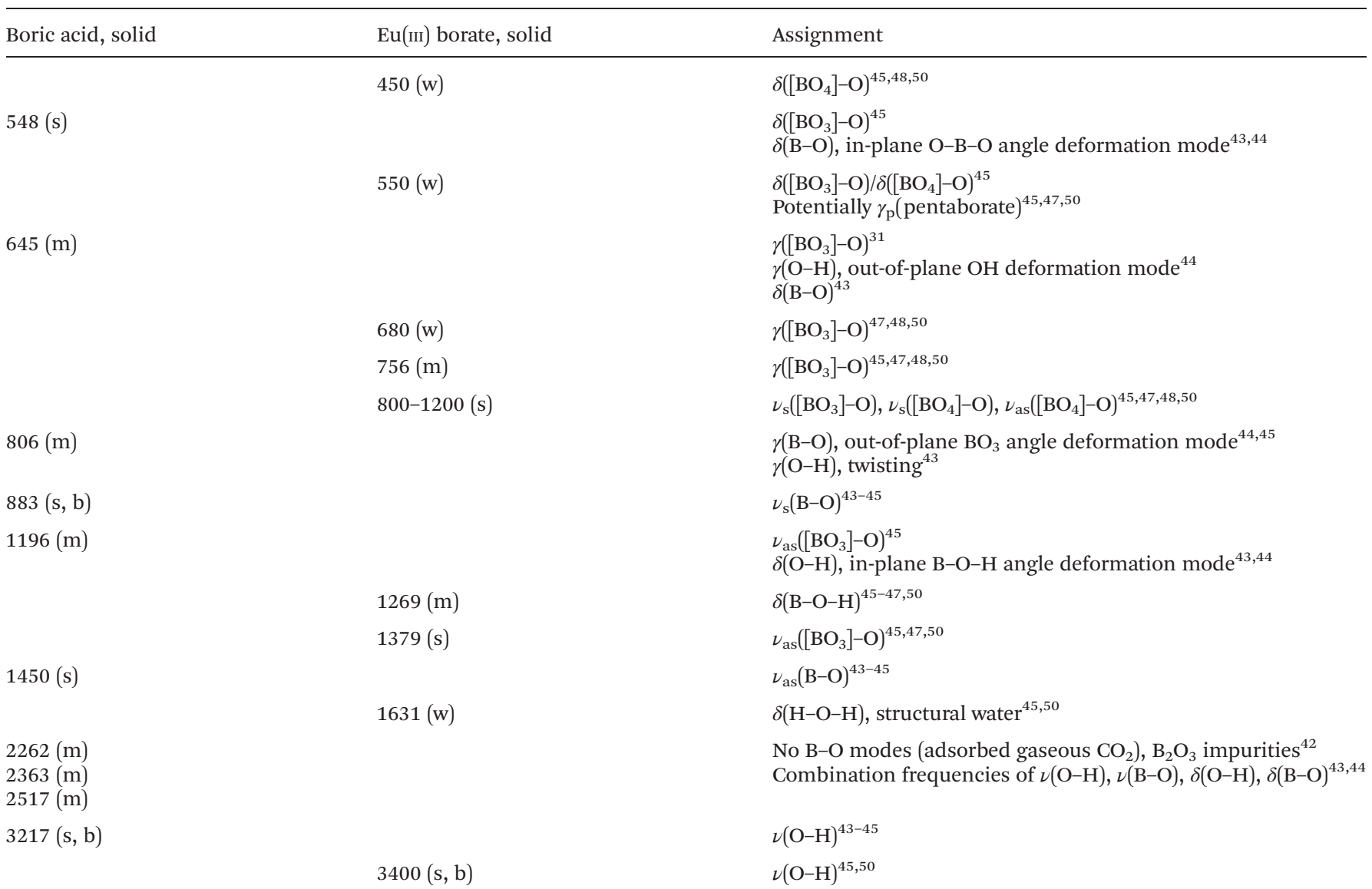

$\mathrm{b}=$ broad, $\mathrm{m}=$ middle, $\mathrm{s}=$ strong, $\mathrm{w}=$ weak, $\left[\mathrm{BO}_{3}\right]=$ trigonal planar boron center, $\left[\mathrm{BO}_{4}\right]=$ tetrahedral boron center, $\nu=$ stretching vibration, $\delta=$ in-plane bending, $\gamma=$ out-of-plane bending.

Besides the vibration modes of trigonal planar boron $\left[\mathrm{BO}_{3}\right]$ units the solid $\mathrm{Eu}(\mathrm{III})$ borate showed vibration modes of tetrahedral boron $\left[\mathrm{BO}_{4}\right]$ units (Fig. $7 \mathrm{a}$, Table 3). The assignment of these modes (Table 3) was based on literature data. ${ }^{45-50}$ Fur- thermore, in the literature so-called pulse vibrations are described being typical of different polyborate structures. ${ }^{45}$ Pulse vibrations of tri-, tetra-, penta- and hexaborates occur in the wavenumber range of $650 \mathrm{~cm}^{-1}$ to $530 \mathrm{~cm}^{-1}{ }^{45}$ In this 

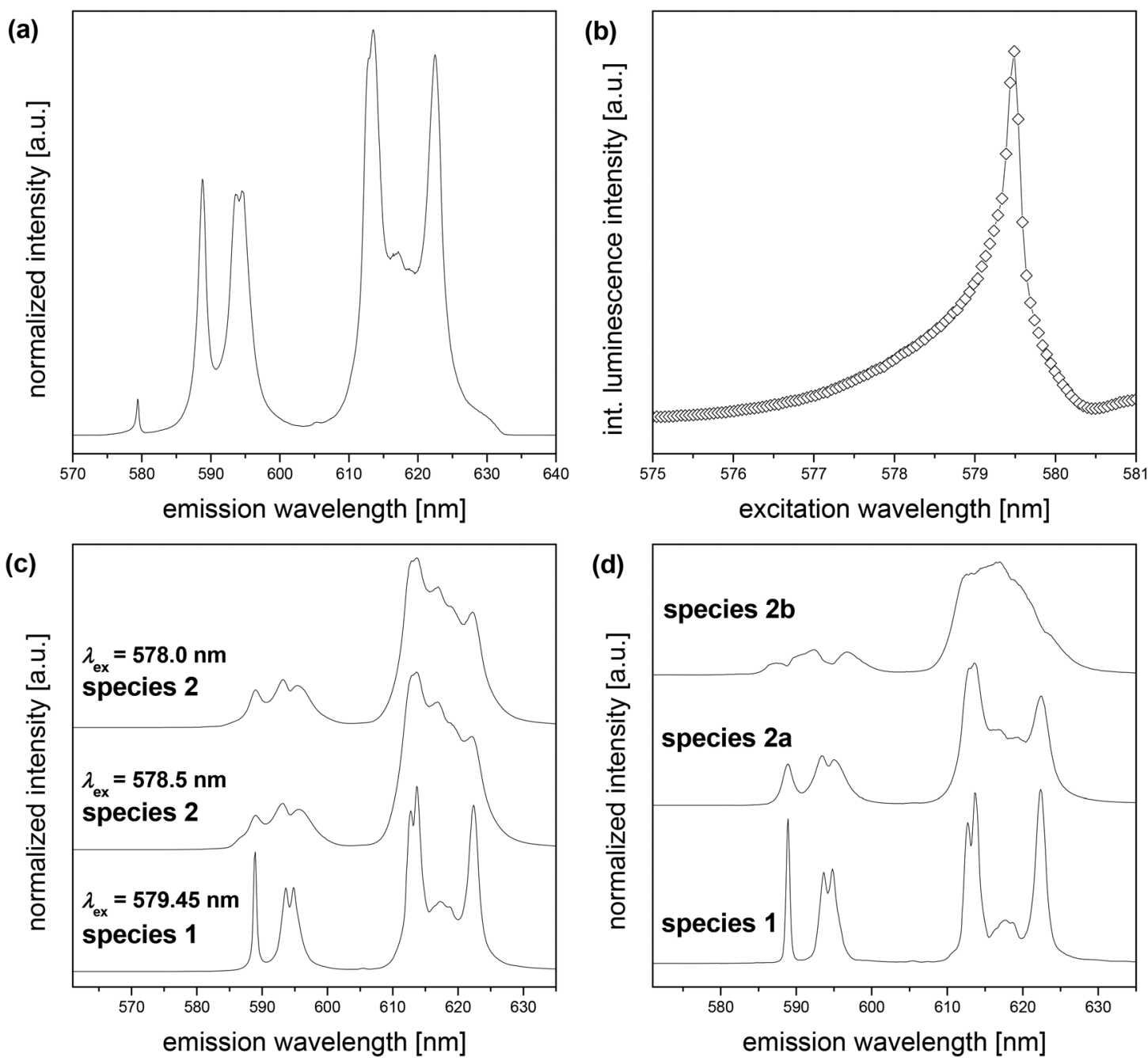

Fig. 8 Solid-state TRLFS of the solid Eu(III) borate. (a) Emission spectrum at room temperature $\left(T=22^{\circ} \mathrm{C}\right)$ excited at $\lambda_{\text {ex }}=394 \mathrm{~nm}$, (b) excitation spectrum at low temperature $\left(T<5 \mathrm{~K}\right.$ ), (c) emission spectra excited at $\lambda_{\text {ex }}=578.0 \mathrm{~nm}, 578.50 \mathrm{~nm}$ and $579.45 \mathrm{~nm}$, respectively, and (d) emission spectra determined from the PARAFAC of the time-resolved spectra at low temperature $(T<5 \mathrm{~K})$ excited at $\lambda_{\mathrm{ex}}=578.50 \mathrm{~nm}$ and $579.45 \mathrm{~nm}$, respectively.

range one vibration band at $550 \mathrm{~cm}^{-1}$ in the measured IR spectrum of the solid Eu(III) borate occurred (Fig. 7b). This could be an indication of a pentaborate structure in the solid $\mathrm{Eu}$ (III) borate. Unfortunately, this is not unambiguous, because this band can be assigned to the bending mode of the $\left[\mathrm{BO}_{3}\right]$ and $\left[\mathrm{BO}_{4}\right]$ units, too (Table 3 ). Nevertheless, the borate structure as the main structure in the isolated Eu(III) solid can be clearly confirmed by IR spectroscopy.

In addition, the vibration band at $1631 \mathrm{~cm}^{-1}$ is assigned to structural water, which obviously exists in the solid Eu(III) borate.

\section{Solid-state TRLFS}

The europium luminescence spectrum of the solid Eu(III) borate at room temperature $\left(\lambda_{\mathrm{ex}}=394.0 \mathrm{~nm}\right)$ is shown in Fig. 8a. This spectrum is comparable to that of the solid Eu(III) borate in suspension (see Fig. 6a). An asymmetrically shaped excitation spectrum of the solid Eu(III) borate has to be noted (Fig. 8b). From this asymmetry the presence of more than one
$\mathrm{Eu}(\mathrm{III})$ species in the isolated $\mathrm{Eu}(\mathrm{III})$ borate solid is indicated. At $\lambda_{\text {ex }}=394.0 \mathrm{~nm}$ all Eu(III) species present in the sample were excited. In order to discriminate the contributions of different species to the overall luminescence, site-selective measurements of the solid Eu(III) borate were performed. The excitation was carried out at $\lambda_{\mathrm{ex}}=579.45 \mathrm{~nm}$ (peak maximum in the excitation spectrum, see Fig. $8 \mathrm{~b}$ ) and at lower excitation wavelengths $\left(\lambda_{\mathrm{ex}}=578.50 \mathrm{~nm}\right.$ and $578.0 \mathrm{~nm}$, respectively) to measure further possible europium species and to minimize the contribution of the strongly luminescent species excited at $\lambda_{\mathrm{ex}}=579.45 \mathrm{~nm}$. At room temperature the emission spectra (not shown) and the luminescence lifetimes $\tau$ (Table 4) recorded at different excitation wavelengths are comparable. The determined $\tau \sim 620 \mu \mathrm{s}$ of the europium solid at room temperature (see Table 4) is comparable to that of the Eu(III) borate solid in suspension (see Fig. 6b).

To obtain more information about the species in the solid $\mathrm{Eu}(\mathrm{III})$ borate, emission spectra were recorded at low tempera- 
Table 4 Luminescence lifetimes $\tau$ of the solid Eu(III) borate for excitations at different $\lambda_{\mathrm{ex}}$

\begin{tabular}{|c|c|c|}
\hline & \multicolumn{2}{|c|}{$\begin{array}{l}\text { Excitation wavelength } \\
\lambda_{\mathrm{ex}}[\mathrm{nm}]\end{array}$} \\
\hline & 578.50 & 579.45 \\
\hline $\begin{array}{l}\tau \text { (measured) }[\mu \mathrm{s}], \text { at room } \\
\text { temperature }\left(22^{\circ} \mathrm{C}\right)\end{array}$ & 605 & 636 \\
\hline $\begin{array}{l}\tau \text { (measured) }[\mu \mathrm{s}], \text { at low } \\
\text { temperature }(<5 \mathrm{~K})\end{array}$ & $\begin{array}{l}263 \\
619\end{array}$ & 771 \\
\hline \multirow[t]{2}{*}{$\begin{array}{l}\tau \text { (from PARAFAC) }[\mu \mathrm{s}] \text {, at low } \\
\text { temperature }(<5 \mathrm{~K})\end{array}$} & $\begin{array}{l}335 \\
\text { (species 2b) }\end{array}$ & $\begin{array}{l}717 \\
\text { (species 2a) }\end{array}$ \\
\hline & $\begin{array}{l}717 \\
\text { (species 2a) }\end{array}$ & $\begin{array}{l}882 \\
\text { (species 1) }\end{array}$ \\
\hline
\end{tabular}

ture $(T<5 \mathrm{~K})$. Compared to the emission spectra at room temperature the spectra at low temperature are much better resolved and a potential splitting of the luminescence bands is more clearly visible (compare Fig. 8a and 8c). Consequently, more information, for instance about the species and the molecular environment of the $\mathrm{Eu}(\mathrm{III})$ in the solid, can be extracted.

At low temperature $(T<5 \mathrm{~K})$ the excitation of europium was carried out at $\lambda_{\mathrm{ex}}=579.45 \mathrm{~nm}, 578.50 \mathrm{~nm}$, and $578.0 \mathrm{~nm}$, respectively. Depending on the excitation wavelength $\lambda_{\mathrm{ex}}$ two different europium species were identified (Fig. 8c). At $\lambda_{\mathrm{ex}}=$ $579.45 \mathrm{~nm}$ the obtained emission spectrum can be assigned to the $\mathrm{Eu}(\mathrm{III})$ borate (named as species 1) as the major species in the solid, because the spectrum shape is comparable to the spectrum of the solid Eu(III) borate in suspension (Fig. 6a). In contrast to the excitation at $\lambda_{\mathrm{ex}}=579.45 \mathrm{~nm}$ distinctly different emission spectra were recorded at $\lambda_{\mathrm{ex}}=578.0 \mathrm{~nm}$ and $578.50 \mathrm{~nm}$ (Fig. 8c). Both spectra obtained at $\lambda_{\mathrm{ex}}=578.0 \mathrm{~nm}$ and $578.50 \mathrm{~nm}$ are identical and are assigned to at least one further europium solid species (named species 2). Identical spectra resulting from different excitation wavelengths are expected for amorphous materials. ${ }^{51}$

In addition, the luminescence decay kinetic at different excitation wavelengths and low temperatures $(T<5 \mathrm{~K})$ was measured. At $\lambda_{\mathrm{ex}}=579.45 \mathrm{~nm}$ one luminescence lifetime with $\tau=771 \mu$ s was determined (Table 4), which is slightly higher than its value at room temperature. This effect was observed elsewhere before, ${ }^{52}$ and can be ascribed to a reduction of radiationless deactivation processes at low temperature. Moreover, at $\lambda_{\mathrm{ex}}=578.50 \mathrm{~nm}$ two luminescence lifetimes were found $\left(\tau_{1}=619 \mu \mathrm{s}\right.$ and $\tau_{2}=263 \mu \mathrm{s}$, Table 4$)$. This indicates that more than one species are observed with $\lambda_{\mathrm{ex}}=578.0 \mathrm{~nm}$ and $578.50 \mathrm{~nm}$. The luminescence of species 1 and species 2 could spectrally overlap or even a third species may have to be considered.

From the PARAFAC of the time-resolved spectra of the solid $\mathrm{Eu}(\mathrm{III})$ borate at low temperature three europium species were clearly determined (Fig. 8d). One species is quite similar to the measured species 1 (compare Fig. $8 \mathrm{c}$ and $8 \mathrm{~d}$ ). It seems that the measured spectrum of species 2 (Fig. $8 \mathrm{c}$ ) is a spectrum com- posed of two species. The PARAFAC was able to separate these two species (named species 2a and 2b, Fig. 8d). Furthermore, it is possible to estimate the contribution of each species to the luminescence signal (Fig. S4 $\dagger$ ). The PARAFAC of the timeresolved data at $\lambda_{\mathrm{ex}}=579.45 \mathrm{~nm}$ showed that species 2a exists as a minor component in addition to species 1 . Species $2 \mathrm{~b}$ does not contribute to the luminescence signal. Because species 1 dominates the luminescence at $\lambda_{\mathrm{ex}}=579.45 \mathrm{~nm}$, only a monoexponential decay was measured (see above). With $\lambda_{\mathrm{ex}}=$ $578.5 \mathrm{~nm}$, species $2 \mathrm{~b}$ contributes to the luminescence in comparable amounts like species 2a (result of the PARAFAC, Fig. S4 $\dagger$ ), which leads to the observed biexponential luminescence decay (see above). Species 1 does not contribute to the luminescence at $\lambda_{\mathrm{ex}}=578.5 \mathrm{~nm}$ (Fig. S4 $\dagger$ ).

From the splitting pattern of the luminescence bands of the europium emission spectra, structural information on the europium environment can be obtained. ${ }^{51,53-56}$

The spectrum of species 1 (measured and determined by PARAFAC, Fig. 8c and 8d, respectively) shows that the ${ }^{5} \mathrm{D}_{0} \rightarrow{ }^{7} \mathrm{~F}_{1}$ luminescence band split into three peaks and the ${ }^{5} \mathrm{D}_{0} \rightarrow{ }^{7} \mathrm{~F}_{2}$ luminescence band split into five peaks. The ${ }^{5} \mathrm{D}_{0} \rightarrow{ }^{7} \mathrm{~F}_{1}$ and ${ }^{5} \mathrm{D}_{0} \rightarrow{ }^{7} \mathrm{~F}_{2}$ luminescence bands in the by PARAFAC determined spectrum of species 2a show similar splitting patterns to those described for species 1 . This indicates a local europium environment with low symmetry $\left(C_{1}, C_{2} \text { or } C_{\mathrm{S}}\right)^{53}$ for species 1 and species $2 \mathrm{a}$. The by PARAFAC separated spectrum of species $2 \mathrm{~b}$ does not show a clear splitting pattern and the symmetry determination of the local europium environment is difficult. It seems that the ${ }^{5} \mathrm{D}_{0} \rightarrow{ }^{7} \mathrm{~F}_{1}$ luminescence band is split into three peaks and the ${ }^{5} \mathrm{D}_{0} \rightarrow{ }^{7} \mathrm{~F}_{2}$ luminescence band into four peaks. This also indicates the low symmetry of the local europium environment $\left(C_{2 \mathrm{v}}\right)^{53}$

Species $2 \mathrm{a}$ is likely a borate species, too. The spectrum shape and luminescence lifetime of species $2 \mathrm{a}$ are comparable to that of species 1 (Table 4, Fig. 8d). The shape of the europium emission spectrum and the luminescence lifetime of species $2 \mathrm{~b}$ point to a $\mathrm{Eu}_{2}\left(\mathrm{CO}_{3}\right)_{3} \cdot n \mathrm{H}_{2} \mathrm{O}$ species. ${ }^{57}$ It is assumed that species $2 \mathrm{a}$ and $2 \mathrm{~b}$ are byproducts of the $\mathrm{Eu}(\mathrm{III})$ borate precipitation.

\section{Europium to boron ratio in the solid}

The boron-europium-sodium ratio was 14.15 : 2.55 : 1. Considering the solid sodium borate phase (see discussion of the powder XRD results above) and minor europium species (see discussion of the solid-state TRLFS results above) the major Eu(III) borate solid species is assumed to be a $\mathrm{Eu}(\mathrm{III})$ pentaborate species.

\section{Conclusion}

This work deals with the very interesting but complex Eu(III)$\mathrm{B}(\mathrm{OH})_{3} /($ poly $)$ borate system at $\mathrm{pH} \leq 6, I=0.1 \mathrm{M}$. Some of the main results shall be summarized. 


\section{Complexation in aqueous solution}

Polyborates, more precisely tri- and pentaborates with one binding site, which occur under the investigated conditions, show a weak complexation of $\mathrm{Eu}(\mathrm{III})\left(\lg \beta_{11} \sim 2\right)$.

\section{Solid formation}

The formation of a $\mathrm{Eu}(\mathrm{III})$ solid phase involving polyborates was observed. To the best of our knowledge this is the first time that such a phase formation starting from a weak Ln(III) polyborate complex has been described at $\mathrm{pH}$ 6. Recently, a similar effect was observed at alkaline $\mathrm{pH}$ (see above). ${ }^{40}$

\section{Possible impact of (poly)borates on the mobilization of An(III) in a nuclear waste repository}

Interpreting the complexation results, borates should have a minor mobilization potential for trivalent actinides at least in the slightly acidic to neutral $\mathrm{pH}$ range because the complexation is very weak in comparison with other complexation reactions, e.g., with carbonate and hydroxide ligands. Furthermore, the formation of solid (poly)borate phases already at slightly acidic $\mathrm{pH}$ should support the immobilization of trivalent actinides.

Future research is definitely required for explaining the actinide-borate interactions, particularly in the alkaline $\mathrm{pH}$ range. Furthermore, other actinides such as uranium and oxidation states of actinides above +3 have to be considered in this context.

\section{Acknowledgements}

This work was funded by the Federal Ministry of Economics and Energy (BMWi) under contract numbers 02E11021 and 02E11011. The authors would like to thank A. Ritter (HZDR) for ICP-MS and AAS analyses, K. Heim (HZDR) for IR measurements, and S. Labs (FZ Jülich) and Ch. Hennig (HZDR) for XRD measurements and analysis. Powder XRD measurements were conducted at the PETRA III facility, beamline P02.1, of the Deutsches Elektronen Synchrotron (DESY) Hamburg, Germany under proposal I-20130337.

\section{References}

1 M. Borkowski, M. Richmann, D. T. Reed and Y. Xiong, Radiochim. Acta, 2010, 98, 577-582.

2 W. G. Woods, Environ. Health Perspect., 1994, 102(Suppl 7), $5-11$.

3 J. F. Lucchini, M. Borkowski, M. K. Richmann, S. Ballard and D. T. Reed, J. Alloys Compd., 2007, 444/445, 506-511.

4 M. J. Polinski, D. J. Grant, S. Wang, E. V. Alekseev, J. N. Cross, E. M. Villa, W. Depmeier, L. Gagliardi and T. E. Albrecht-Schmitt, J. Am. Chem. Soc., 2012, 134, 1068210692.
5 M. J. Polinski, S. Wang, E. V. Alekseev, W. Depmeier and T. E. Albrecht-Schmitt, Angew. Chem., Int. Ed., 2011, 50, 8891-8894.

6 M. J. Polinski, S. Wang, E. V. Alekseev, W. Depmeier, G. Liu, R. G. Haire and T. E. Albrecht-Schmitt, Angew. Chem., Int. Ed., 2012, 51, 1869-1872.

7 S. Wang, E. V. Alekseev, W. Depmeier and T. E. AlbrechtSchmitt, Inorg. Chem., 2011, 50, 2079-2081.

8 M. J. Polinski, E. M. Villa and T. E. Albrecht-Schmitt, Coord. Chem. Rev., 2014, 266-267, 16-27.

9 T. Straaso, A.-C. Dippel, J. Becker and J. Als-Nielsen, J. Synchrotron Radiat., 2014, 21, 119-126.

10 A. P. Hammersley, S. O. Svensson, M. Hanfland, A. N. Fitch and D. Hausermann, High Press. Res., 1996, 14, 235-248.

11 Lanthanide Probes in Life, Chemical and Earth Sciences: Theory and Practice, ed. J.-C. G. Bünzli and G. R. Choppin, Elsevier Science B.V., Amsterdam, 1989.

12 W. D. Horrocks and D. R. Sudnick, J. Am. Chem. Soc., 1979, 101, 334-340.

13 T. Kimura and G. R. Choppin, J. Alloys Compd., 1994, 213/214, 313-317.

14 C. Moulin, J. Wei, P. Van Iseghem, I. Laszak, G. Plancque and V. Moulin, Anal. Chim. Acta, 1999, 396, 253-261.

15 G. Plancque, V. Moulin, P. Toulhoat and C. Moulin, Anal. Chim. Acta, 2003, 478, 11-22.

16 B. Marmodée, K. Jahn, F. Ariese, C. Gooijer and M. U. Kumke, J. Phys. Chem. A, 2010, 114, 13050-13054.

17 P. Gans, A. Sabatini and A. Vacca, Hyperquad Simulation and Speciation, Protonic Software, Leeds, 2009.

18 P. Gans, A. Sabatini and A. Vacca, Hyperquad suite of programs, Protonic Software, Leeds, 2008.

19 A. Heller, A. Barkleit, H. Foerstendorf, S. Tsushima, K. Heim and G. Bernhard, Dalton Trans., 2012, 41, 1396913983.

20 A. Shokrollahi, M. Montazerozohori, T. Mehrpour, H. Tavallali, B. Z. Khafri and Z. Montaseri, Quim. Nova, 2013, 36, 1354-1359.

21 L. E. Santos-Figueroa, M. E. Moragues, M. M. M. Raposo, R. M. F. Batista, R. C. M. Ferreira, S. P. G. Costa, F. Sancenon, R. Martinez-Manez, J. Soto and J. V. Ros-Lis, Tetrahedron, 2012, 68, 7179-7186.

22 A. Günther and G. Bernhard, HZDR-IRE Annual Report 2012, HZDR-030, ISSN 2191-8716, Dresden, 2013.

23 C. A. Andersson and R. Bro, Chemom. Intell. Lab. Syst., 2000, 52, 1-4.

24 T. Saito, H. Sao, K. Ishida, N. Aoyagi, T. Kimura, S. Nagasaki and S. Tanaka, Environ. Sci. Technol., 2010, 44, 5055-5060.

25 R. M. Callejón, J. M. Amigo, E. Pairo, S. Garmón, J. A. Ocana and M. L. Morales, Talanta, 2012, 88, 456-462.

26 K. Ishida, T. Saito, N. Aoyagi, T. Kimura, R. Nagaishi, S. Nagasaki and S. Tanaka, J. Colloid Interface Sci., 2012, 374, 258-266.

27 N. Ingri, Acta Chem. Scand., 1962, 16, 439-448.

28 N. Ingri, G. Lagerström, M. Frydman and L. G. Sillén, Acta Chem. Scand., 1957, 11, 1034-1058. 
29 I. Tsuyumoto, T. Oshio and K. Katayama, Inorg. Chem. Commun., 2007, 10, 20-22.

30 J. L. Anderson, E. M. Eyring and M. P. Whittaker, J. Phys. Chem., 1964, 68, 1128-1132.

31 N. Ingri, Acta Chem. Scand., 1963, 17, 573-580.

32 A. Hertam, Thesis, Freiberg University of Mining and Technology, 2011.

33 T. Hirao, M. Kotaka and H. Kakihana, J. Inorg. Nucl. Chem., 1979, 41, 1217-1220.

34 L. Maya, Inorg. Chem., 1976, 15, 2179-2184.

35 R. K. Momii and N. H. Nachtrieb, Inorg. Chem., 1967, 6, 1189-1192.

36 Y. Zhou, C. Fang, Y. Fang and F. Zhu, Spectrochim. Acta, Part A, 2011, 83, 82-87.

37 J. E. Spessard, J. Inorg. Nucl. Chem., 1970, 32, 2607-2613.

38 R. Janda and G. Heller, Z. Naturforsch., B: J. Chem. Sci., 1979, 34, 1078-1083.

39 M. Herm, X. Gaona, T. Rabung, C. Crepin, V. Metz, M. Altmaier and H. Geckeis, Book of Abstracts of the Migration 2013, Brighton (UK), 2013.

40 K. Hinz, M. Altmaier, X. Gaona, T. Rabung, D. Schild, C. Adam and H. Geckeis, Book of Abstracts of the Migration 2013, Brighton (UK), 2013.

41 S. Menchetti, C. Sabelli, A. Stoppioni and R. Trosti-Ferroni, Neues Jahrb. Mineral., Abh., 1983, 148, 163-180.

42 E. F. Medvedev and A. S. Komarevskaya, Glass Ceram., 2007, 64, 42-46.

43 J. L. Parsons and M. E. Milberg, J. Am. Ceram. Soc., 1960, 43, 326-330.

44 D. E. Bethell and N. Sheppard, Trans. Faraday Soc., 1955, 51, 9-15.
45 L. Jun, X. Shuping and G. Shiyang, Spectrochim. Acta, Part A, 1995, 51, 519-532.

46 E. L. Belokoneva, A. G. Ivanova, S. Y. Stefanovich, O. V. Dimitrova and V. S. Kurazhkovskaya, Crystallogr. Rep., 2004, 49, 603-613.

47 S. Hua-Yu, Z. Yan, H. Ya-Xi, S. Wei and M. Jin-Xiao, Chin. J. Struct. Chem., 2010, 29, 1387-1393.

48 R. Janda and G. Heller, Spectrochim. Acta, Part A, 1980, 36, 997-1001.

49 S. Lemanceau, G. Bertrand-Chadeyron, R. Mahiou, M. El-Ghozzi, J. C. Cousseins, P. Conflant and R. N. Vannier, J. Solid State Chem., 1999, 148, 229-235.

50 Z. Lixia, Y. Tao, W. Jiang and G. Shiyang, Russ. J. Inorg. Chem., 2007, 52, 1786-1792.

51 K. S. Holliday and T. Stumpf, Environ. Radiochem. Anal., 2011, IV, 30-39.

52 S. Kuke, B. Marmodée, S. Eidner, U. Schilde and M. U. Kumke, Spectrochim. Acta, Part A, 2010, 75, 13331340.

53 C. Görller-Walrand and K. Binnemans, Handbook on the Physics and Chemistry of Rare Earths, ed. K. A. Gschneidner Jr. and L. Eyring, Elsevier Science B. V., Amsterdam, 1996, vol. 23.

54 M. Schmidt, T. Stumpf, C. Walther, H. Geckeis and T. Fanghänel, Dalton Trans., 2009, 6645-6650.

55 R. Ternane, M. Ferid, G. Panczer, M. Trabelsi-Ayadi and G. Boulon, Opt. Mater., 2005, 27, 1832-1838.

56 B. Piriou, A. Elfakir and M. Quarton, J. Lumin., 2001, 93, 17-26.

57 W. Runde, C. Van Pelt and P. G. Allen, J. Alloys Compd., 2000, 303/304, 182-190. 